\title{
Cerebellar ataxia, neuropathy, hearing loss, and intellectual disability due to AIFM1 mutation
}

Massimo Pandolfo, MD, Myriam Rai, PhD, Gauthier Remiche, MD, PhD, Laurence Desmyter, PhD, and Isabelle Vandernoot, MD

Neurol Genet 2020;6:e420. doi:10.1212/NXG.0000000000000420
Correspondence

Dr. Pandolfo

massimo.pandolfo@ulb.be

\section{Abstract}

\section{Objective}

To describe the clinical and molecular genetic findings in a family segregating a novel mutation in the AIFM1 gene on the $\mathrm{X}$ chromosome.

\section{Methods}

We studied the clinical features and performed brain MRI scans, nerve conduction studies, audiometry, cognitive testing, and clinical exome sequencing (CES) in the proband, his mother, and maternal uncle. We used in silico tools, $\mathrm{X}$ chromosome inactivation assessment, and Western blot analysis to predict the consequences of an AIFM1 variant identified by CES and demonstrate its pathogenicity.

\section{Results}

The proband and his maternal uncle presented with childhood-onset nonprogressive cerebellar ataxia, hearing loss, intellectual disability (ID), peripheral neuropathy, and mood and behavioral disorder. The proband's mother had mild cerebellar ataxia, ID, and mood and behavior disorder, but no neuropathy or hearing loss. The 3 subjects shared a variant (c.1195G>A; p.Gly399Ser) in exon 12 of the AIFM1 gene, which is not reported in the exome/genome sequence databases, affecting a critical amino acid for protein function involved in $\mathrm{NAD}(\mathrm{H})$ binding and predicted to be pathogenic with very high probability by variant analysis programs. $\mathrm{X}$ chromosome inactivation was highly skewed in the proband's mother. The mutation did not cause quantitative changes in protein abundance.

\section{Conclusions}

Our report extends the molecular and phenotypic spectrum of AIFM1 mutations. Specific findings include limited progression of neurologic abnormalities after the first decade and the coexistence of mood and behavior disorder. This family also shows the confounding effect on the phenotype of nongenetic factors, such as alcohol and drug use and side effects of medication. 


\section{Glossary}

CES = clinical exome sequencing; $\mathbf{C R}=$ creatine; ID = intellectual disability; MRS = magnetic resonance spectroscopy; PBMC = peripheral blood mononuclear cell; $\mathbf{S C A}=$ spinocerebellar ataxia .

We describe a family segregating a complex syndrome because of a previously unreported mutation in the AIFM1 (apoptosis-inducing factor, mitochondrion-associated, 1) gene, encoding a homodimeric flavoprotein tethered to the mitochondrial inner membrane that is required to maintain the mitochondrial respiratory complex I. AIFM1 has a rotenone-sensitive reduced nicotinamide adenine dinucleotide $(\mathrm{NADH}):$ Ubiquinone oxidoreductase activity, whose functional role remains unclear. ${ }^{1}$ In addition, under conditions of mitochondrial stress, a cleaved fragment of AIFM1 is also implicated in caspase-independent programmed cell death induction. ${ }^{2}$ Mutations may affect one or both of these functions. ${ }^{3}$ Cerebellar atrophy is prominent in the Harlequin ( $\left.\mathrm{Hq}\right)$ mouse, a spontaneous Aifm1 mutant, ${ }^{4}$ but is not a common feature of the multiple phenotypes associated with AIFM1 mutations in humans. These include a severe neonatal mitochondrial encephalomyopathy, ${ }^{5}$ a more slowly progressive encephalopathy, ${ }^{6}$ the association of sensorineural hearing loss and axonal neuropathy called Cowchock syndrome, ${ }^{7}$ other "mitochondrial" phenotypes of variable severity and symptoms, and other unique presentations as infantile motor neuron disease, ${ }^{8}$ distal motor neuropathy, ${ }^{9}$ ventriculomegaly, and myopathy. ${ }^{10}$ Cerebellar ataxia, mostly of childhood onset, has been occasionally reported in association with other phenotypes of variable severity. ${ }^{6,8,10,11}$ In this article, we extend the spectrum of AIFM1-related phenotypes and report a novel AIFM1 mutation affecting the $\mathrm{NAD}(\mathrm{H})$ binding site.

\section{Methods}

We collected DNA samples on 3 family members. Initial genetic screening involved testing the proband for spinocerebellar ataxias (SCAs) caused by cytosine-adenosineguanosine repeat expansions (SCA1, 2, 3, 6, 7, 17). Because this was negative, next generation sequencing of 3,638 genes associated with pathologic human phenotypes (clinical exome sequencing $[\mathrm{CES}]$ ) was performed on all 3 individuals' DNA.

$\mathrm{X}$ chromosome inactivation in the proband's mother peripheral blood mononuclear cells (PBMCs) was assessed by amplification of the cytosine-adenosine-guanosine repeat in the androgen receptor gene before and after cleavage with the methylation-sensitive enzymes HpaII and CfoI.

For Western blot analysis, PBMCs from the proband and his mother were isolated by centrifugation on Ficoll, mechanically lysed and separated into a nuclear and cytoplasmic fraction by centrifugation. AIFM1 was detected using a goat polyclonal primary antibody (Novus Biologicals, Abingdon, UK) and chemiluminescence detection.

\section{Standard protocol approvals, registrations, and patient consents}

Patients provided written informed consent for genetic analysis and for the use of their coded data for research purposes, as approved by the Ethics Committee of the Hôpital Erasme, Brussels, Belgium.

\section{Data availability}

Coded clinical and genetic data not allowing patient identification and details on pipeline and filtering of CES results are available on request.

\section{Results}

\section{Clinical presentation}

The family tree is shown in figure 1 . No information is available on the maternal grandparents of the proband. In the proband, instability and clumsiness were first noticed when he was 2 years old. At age 10, he had severe gait and limb ataxia, dysarthria, and abnormal eye movements with jerky pursuit and slow saccades. Brain MRI was performed at age 2, 4, 7, 9, and 13 years. Although the first 2 investigations were reported to be normal, mild cerebellar atrophy was seen at age 7 , which progressed in the following years, affecting both vermis and hemispheres (figure 2, $A$ and $B$ ). Knee and ankle reflexes were absent at age 2, and there was mild leg amyotrophy, suggesting that polyneuropathy was initially responsible for motor symptoms. Cognitive development was considered normal until age 2 , and then, it

Figure 1 Family pedigree

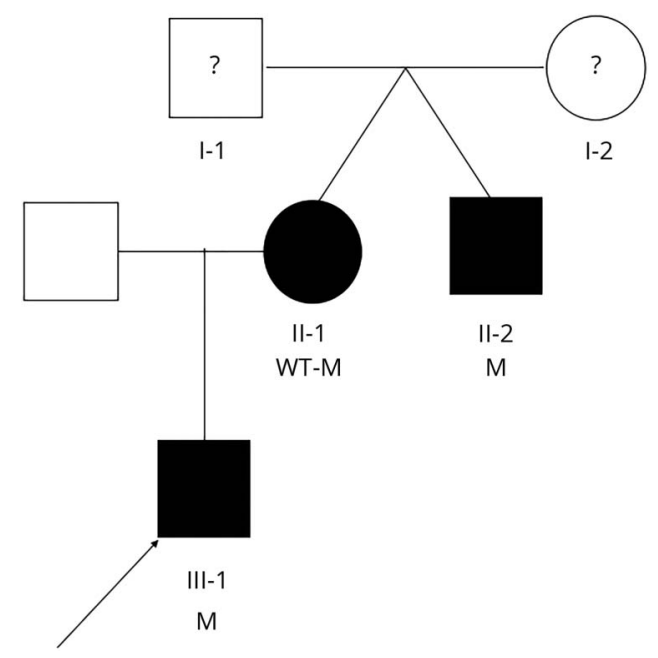

The proband, individual III-1, is indicated with an arrowhead. AIFM1 genotypes are indicated as wt (G399) or M (S399). 


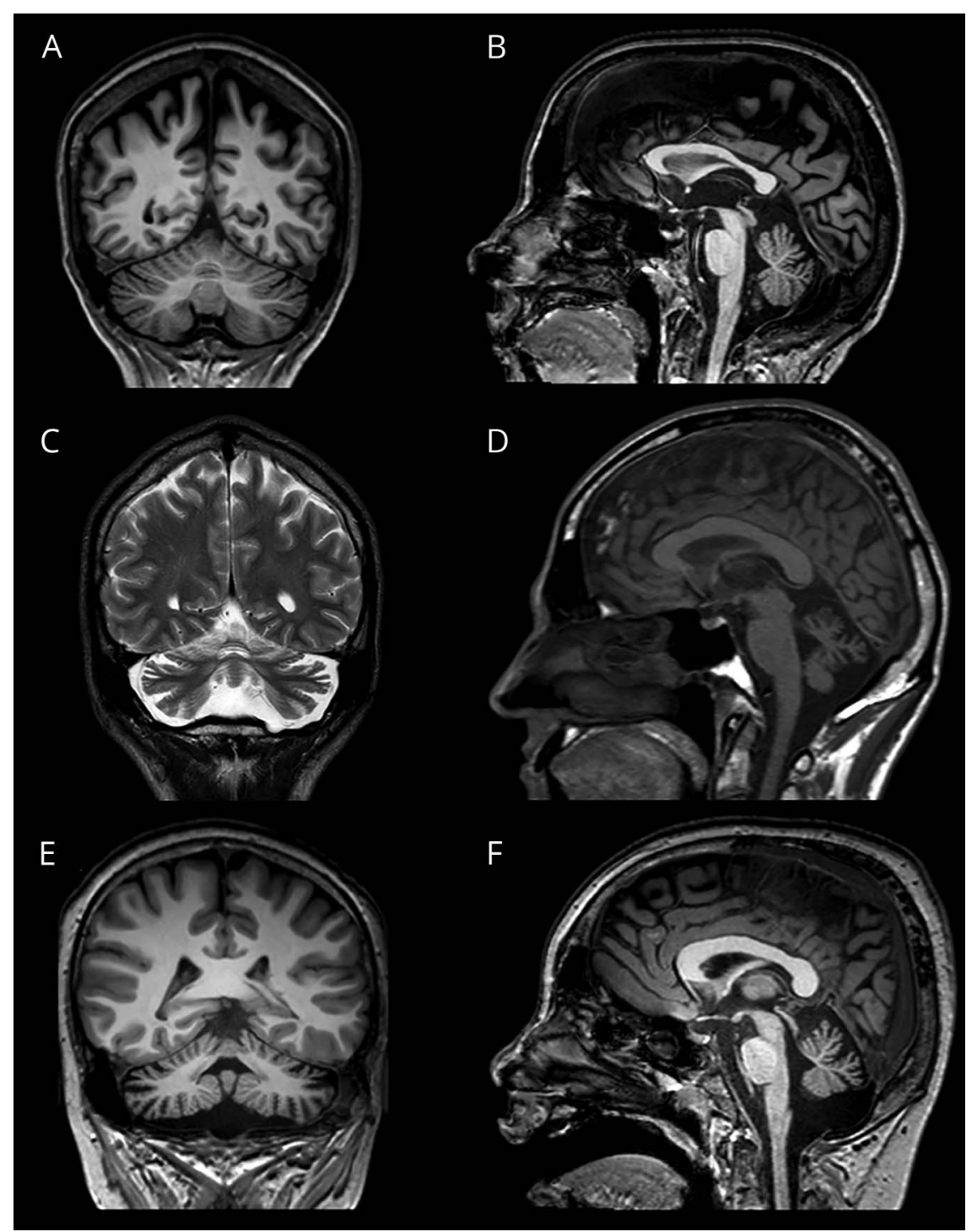

Coronal (A, C, and E) and sagittal (B, D, and F) T1(A-F) and T2-weighted (C) brain MRI images from the proband at age 13 (A and $B$ ), his maternal uncle at age 42 ( $C$ and $D)$, and proband's mother at age 42 ( $E$ and F). Notice the mild cerebellar atrophy in the proband's mother and the moderate cerebellar atrophy in the proband and his uncle. stagnated. At age 10, he had a total IQ of 50, with no significant difference between verbal and perceptual reasoning scores. Hearing was still normal at age 8 , but hearing loss was present at age 10. The clinical picture remained stable in the second decade, with some improvement with intense rehabilitation.

The proband's mother had mild truncal and limb ataxia, dysarthria, mild loss of vibration sense at external malleoli, and a bilateral extensor plantar response. Tendon reflexes in her lower limbs were brisk at age 42, then weakened and disappeared by age 46 . Gaze-evoked nystagmus, present at age 42 , also disappeared by age 46 , whereas saccades become slow and hypometric. She had had mood instability and behavioral problems since her adolescence, leading to repeated referrals to psychiatric services. She had received a diagnosis of bipolar disorder and was treated with antidepressants, neuroleptics, and mood stabilizers. A rest and action tremor of her hands was attributed to chronic treatment with valproate as mood stabilizers. Her cognitive function was in the mild intellectual disability (ID) range. She had no hearing loss. Brain MRI at age 43 showed mild cerebellar atrophy (figure 2, C and D). Magnetic resonance spectroscopy (MRS) revealed decreased $\mathrm{N}$-acetyl-aspartate/creatine (CR) and choline/CR ratios in the cerebellum and brainstem, with a detectable lactate peak.

The proband's maternal uncle, twin brother of the proband's mother, when examined in his $40 \mathrm{~s}$ had similar clinical features of childhood-onset ataxia that stopped progressing in the second decade, ID with prominent executive dysfunction, peripheral neuropathy, and deafness. Mood instability and behavioral problems, for which he received antidepressants, neuroleptics, and mood stabilizers, had been prominent since childhood. When seen at age 42 , he had moderate generalized bradykinesia and rigidity, which resolved after stopping neuroleptics and 
valproate. At age 42, MRI showed diffuse cerebellar atrophy, affecting both vermis and hemispheres (figure 2, E and F). Blood lactate was mildly increased on several occasions.

\section{Genetic analyses}

CES revealed a variant (c.1195G>A; p.Gly399Ser) in exon 12 of the AIFM1 gene (NM_004208) on the X chromosome shared by the proband, his maternal uncle, and his mother. This variant is not reported in the literature and is not present in ExAC and gnomAD (supplemental material, links.lww. com/NXG/A254).

AIFM1 has 3 domains: flavin adenine dinucleotide-binding (residues 128-262 and 401-480), NADH-binding (residues 263-400), and C-terminal (residues 481-608) (atlasgeneticsoncology.org//Genes/AIFM1ID44053chXq25.

html). The variant affects a highly conserved glycine that is located in the $\mathrm{NADH}$-binding domain, where it directly interacts with $\mathrm{NADH}$ (figure 3 ). It is predicted to be deleterious by Polyphen-2, SIFT, and MutationTaster, likely preventing or destabilizing $\mathrm{NADH}$ binding to AIFM1, which is needed for its oxidoreductase activity and dimerization. ${ }^{12}$

Following the American College of Medical Genetics guidelines, the variant, even if found in a single family, is classified as likely pathogenic because it is located in a critical and wellestablished functional domain without benign variation (PM1), it is absent from controls in exome and genome

Figure 3 Amino acid change affecting the AIFM1 NAD(H)A binding site

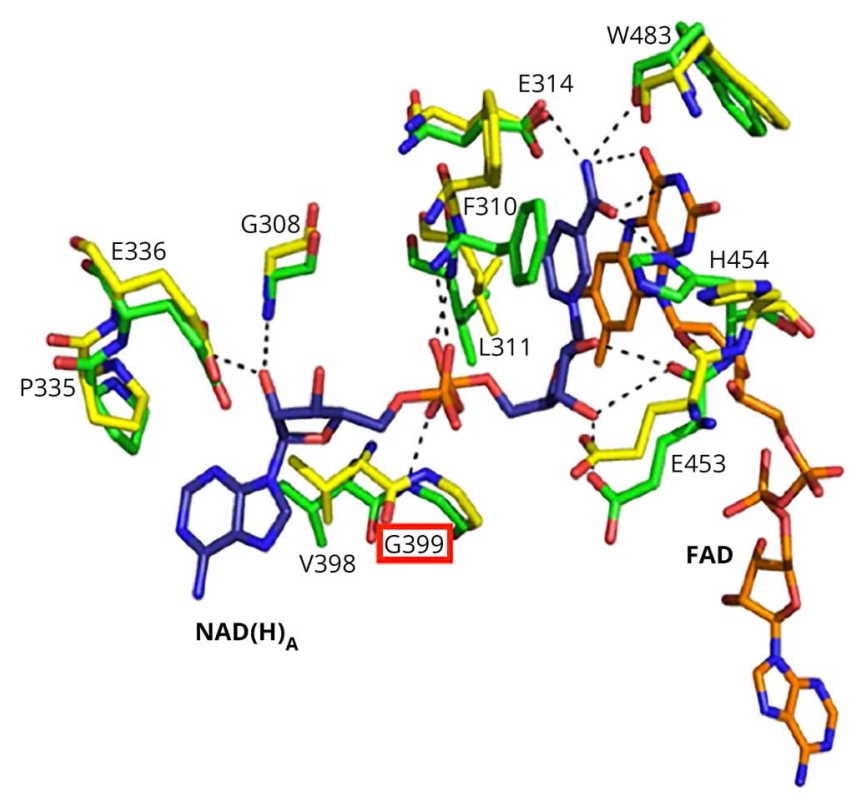

Schematic of the AIFM1 structure around the $\mathrm{NAD}(\mathrm{H})_{\mathrm{A}}$ and FAD binding sites. The mutated $\mathrm{G} 399$ residue (boxed) is directly involved in $N A D(H)$ binding. Adapted with permission from American Chemical Society from Ferreira $P$, et al. ${ }^{12}$ Copyright 2014 American Chemical Society, Washington, DC. All permission requests for this image should be made to the copyright holder. $F A D=$ flavin adenine dinucleotide. databases (PM2), it is a missense variant in a gene that has a low rate of benign missense variation and in which missense variants are a common mechanism of disease (PP2), and multiple lines of computational evidence support a deleterious effect on the gene or gene product (PP3). In addition, the patients' phenotype has highly specific features associated with AIFM1 mutations, in particular axonal polyneuropathy and deafness (PP4). Highly skewed X inactivation in the heterozygous proband's mother (91:9 ratio) further supports the pathogenicity of this variant.

Western blot analysis of AIFM1 (not shown) revealed no difference in size or abundance between the proband, his mother, and normal male and female controls, indicating that the mutation did not affect the synthesis, maturation, or degradation of the protein.

\section{Discussion}

The phenotype of our male patients partially overlaps with Cowchock syndrome because they both have axonal polyneuropathy and deafness in addition to cerebellar ataxia and ID. However, cerebellar atrophy, which is a prominent feature in this family has rarely been reported in human patients with AIFM1 mutation. Interesting, cerebellar ataxia progression essentially occurred in the first decade, followed by stabilization and, in the proband, even improvement with intensive rehabilitation. Treatment with riboflavin, reported to be beneficial in 2 patients with ataxia and AIFM1 mutations, might have provided further improvement. ${ }^{11}$ Whether the mood and behavior disorder also prominent in this family is coincidental, possibly because of an unfavorable environment combined to other genetic risk factors, or a consequence of the mutation remains speculative. However, the very similar psychiatric and cognitive profiles of the proband and his uncle suggest that the mutation may indeed have a predisposing role, if not a causative role.

Of interest all previously reported AIFM1 mutations are recessive, with only hemizygous men being clinically affected, whereas in our family, a heterozygous woman seems to be symptomatic, although in a much milder form than her brother and son. However, in her case, the causative role of the AIFM1 mutation may be questioned. First, highly skewed $\mathrm{X}$ inactivation makes it unlikely that a mutation present in a very small proportion of active $\mathrm{X}$ chromosomes can be disease causing, even if, by affecting $\mathrm{NADH}$ binding, it may prevent dimerization of the protein. In addition, although brain lactate was detected by MRS in this patient, this finding is not specific and cannot prove a role of the mutation in causing her neurologic features. In addition, this patient has a history of alcohol and drug abuse and use of neuroleptics and mood stabilizers, which are likely to have clouded her clinical picture. In this regard, her tremor was clearly induced by valproate, whereas polyneuropathy and mild cerebellar atrophy might have been secondary to alcohol abuse, although we cannot exclude that the AIFM1 mutation may have 
enhanced her vulnerability to these factors. Notably, iatrogenic complications due to neuroleptic treatment also occurred in the proband and in his uncle; a strong reminder of how a variety of factors, including nongenetic ones, may affect the phenotype of a genetic disorder and be potentially misleading in the diagnostic process.

\section{Study funding}

This study was supported by internal funding from the Service of Neurology and of Medical Genetics, Hôpital Erasme, Université Libre de Bruxelles, Brussels, Belgium.

\section{Disclosure}

M. Pandolfo is Deputy Editor for Neurology: Genetics. M. Rai, G. Remiche, L. Desmyter, and I. Vandernoot have nothing to disclose. Go to Neurology.org/NG for full disclosure.

\section{Publication history}

Received by Neurology: Genetics January 7, 2020. Accepted in final form March 7, 2020.

Appendix Authors

\begin{tabular}{lll}
\hline Name & Location & Contribution \\
\hline $\begin{array}{ll}\text { Massimo } \\
\text { Pandolfo, MD }\end{array}$ & $\begin{array}{l}\text { Université Libre de } \\
\text { Bruxelles, Belgium }\end{array}$ & $\begin{array}{l}\text { Data acquisition; study concept } \\
\text { or design; analysis or } \\
\text { interpretation of data; } \\
\text { contribution of vital reagents/ } \\
\text { tools/patients; acquisition of } \\
\text { data; and study supervision }\end{array}$ \\
& & $\begin{array}{l}\text { Analysis or interpretation of data; } \\
\text { contribution of vital reagents/ } \\
\text { tools/patients; and acquisition of } \\
\text { Myriam Rai, } \\
\text { PhD }\end{array}$ \\
& Université Libre de \\
\hline
\end{tabular}

Appendix (continued)

\begin{tabular}{lll}
\hline Name & Location & Contribution \\
\hline $\begin{array}{l}\text { Gauthier } \\
\text { Remiche, MD, } \\
\text { PhD }\end{array}$ & $\begin{array}{l}\text { Université Libre de } \\
\text { Bruxelles, Belgium }\end{array}$ & $\begin{array}{l}\text { Drafting/Revising the manuscript; } \\
\text { and data acquisition }\end{array}$ \\
\hline $\begin{array}{l}\text { Laurence } \\
\text { Desmyter, } \\
\text { PhD }\end{array}$ & $\begin{array}{l}\text { Université Libre de } \\
\text { Bruxelles, Belgium }\end{array}$ & Analysis or interpretation of data \\
\hline $\begin{array}{l}\text { Isabelle } \\
\text { Vandernoot, } \\
\text { MD }\end{array}$ & $\begin{array}{l}\text { Université Libre de } \\
\text { Bruxelles, Belgium }\end{array}$ & $\begin{array}{l}\text { Drafting/revising the manuscript; } \\
\text { data acquisition; and analysis or } \\
\text { interpretation of data }\end{array}$ \\
\hline
\end{tabular}

\section{References}

1. Elguindy MM, Nakamaru-Ogiso E. Apoptosis-inducing factor (AIF) and its family member protein, AMID, are rotenone-sensitive NADH:ubiquinone oxidoreductases (NDH-2). J Biol Chem 2015;290:20815-20826.

2. Susin SA, Lorenzo HK, Zamzami N, et al. Molecular characterization of mitochondrial apoptosis-inducing factor. Nature 1999;397:441-446.

3. Sevrioukova IF. Structure/function relations in AIFM1 variants associated with neurodegenerative disorders. J Mol Biol 2016;428:3650-3665.

4. Klein JA, Longo-Guess CM, Rossmann MP, et al. The harlequin mouse mutation downregulates apoptosis-inducing factor. Nature 2002;419:367-374.

5. Ghezzi D, Sevrioukova I, Invernizzi F, et al. Severe X-linked mitochondrial encephalomyopathy associated with a mutation in apoptosis-inducing factor. Am J Hum Genet 2010;86:639-649.

6. Ardissone A, Piscosquito G, Legati A, et al. A slowly progressive mitochondrial encephalomyopathy widens the spectrum of AIFM1 disorders. Neurology 2015;84:2193-2195.

7. Rinaldi C, Grunseich C, Sevrioukova IF, et al. Cowchock syndrome is associated with a mutation in apoptosis-inducing factor. Am J Hum Genet 2012;91:1095-1102.

8. Diodato D, Tasca G, Verrigni D, et al. A novel AIFM1 mutation expands the phenotype to an infantile motor neuron disease. Eur J Hum Genet 2016;24:463-466.

9. Sancho P, Sánchez-Monteagudo A, Collado A, et al. A newly distal hereditary motor neuropathy caused by a rare AIFM1 mutation. Neurogenetics 2017;18:245-250.

10. Kettwig M, Schubach M, Zimmermann FA, et al. From ventriculomegaly to severe muscular atrophy: expansion of the clinical spectrum related to mutations in AIFM1. Mitochondrion 2015;21:12-18.

11. Heimer G, Eyal E, Zhu X, et al. Mutations in AIFM1 cause an X-linked childhood cerebellar ataxia partially responsive to riboflavin. Eur J Paediatr Neurol 2018;22:93-101.

12. Ferreira P, Villanueva R, Martínez-Júlvez M, et al. Structural insights into the coenzyme mediated monomer-dimer transition of the pro-apoptotic apoptosis inducing factor. Biochemistry 2014;53:4204-4215. 


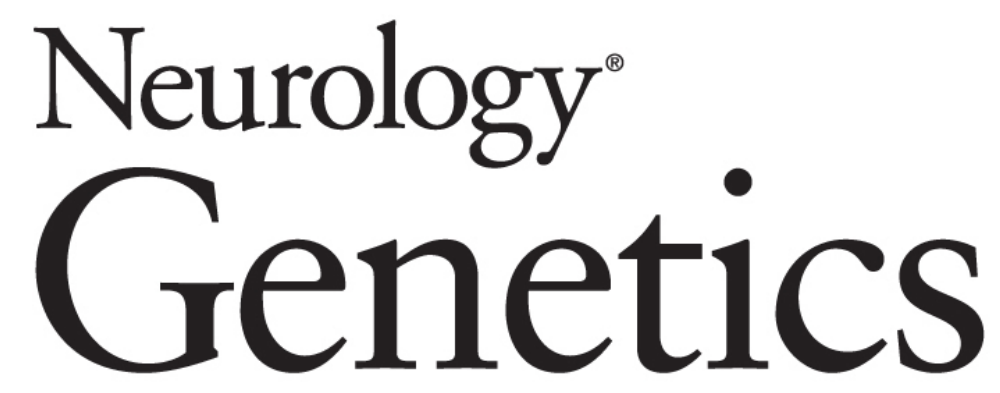

Cerebellar ataxia, neuropathy, hearing loss, and intellectual disability due to AIFM1 mutation

Massimo Pandolfo, Myriam Rai, Gauthier Remiche, et al.

Neurol Genet 2020;6;

DOI 10.1212/NXG.0000000000000420

This information is current as of April 9, 2020

Neurol Genet is an official journal of the American Academy of Neurology. Published since April 2015, it is an open-access, online-only, continuous publication journal. Copyright Copyright ( 2020 The Author(s).

Published by Wolters Kluwer Health, Inc. on behalf of the American Academy of Neurology.. All rights reserved. Online ISSN: 2376-7839.

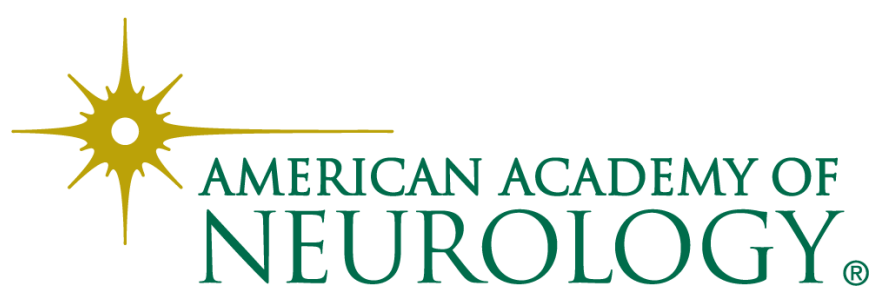




\section{Updated Information \& Services}

References

Citations

Subspecialty Collections

Permissions \& Licensing

Reprints including high resolution figures, can be found at: http://ng.neurology.org/content/6/3/e420.full.html

This article cites 12 articles, 1 of which you can access for free at: http://ng.neurology.org/content/6/3/e420.full.html\#\#ref-list-1

This article has been cited by 1 HighWire-hosted articles: http://ng.neurology.org/content/6/3/e420.full.html\#\#otherarticles

This article, along with others on similar topics, appears in the following collection(s):

\section{Cerebellum}

http://ng.neurology.org//cgi/collection/cerebellum

Gait disorders/ataxia

http://ng.neurology.org//cgi/collection/gait_disorders_ataxia

\section{Mitochondrial disorders}

http://ng.neurology.org//cgi/collection/mitochondrial_disorders

Spinocerebellar ataxia

http://ng.neurology.org//cgi/collection/spinocerebellar_ataxia

Information about reproducing this article in parts (figures,tables) or in its entirety can be found online at:

http://ng.neurology.org/misc/about.xhtml\#permissions

Information about ordering reprints can be found online:

http://ng.neurology.org/misc/addir.xhtml\#reprintsus

Neurol Genet is an official journal of the American Academy of Neurology. Published since April 2015, it is an open-access, online-only, continuous publication journal. Copyright Copyright ( 2020 The Author(s). Published by Wolters Kluwer Health, Inc. on behalf of the American Academy of Neurology.. All rights reserved. Online ISSN: 2376-7839.

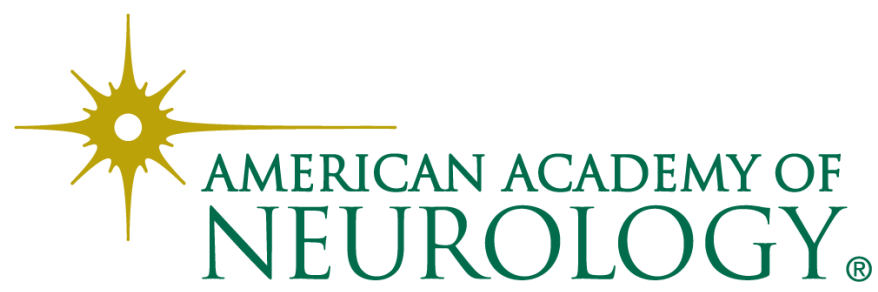

